\title{
The Differential Heritability of Regular Tobacco Use Based on Method of Administration
}

\author{
J. Eric Schmitt, ${ }^{1,2}$ Carol A. Prescott, ${ }^{1,3,4}$ Charles O. Gardner, ${ }^{1,3}$ Michael C. Neale, ${ }^{1,2,3,4}$ and Kenneth S. Kendler ${ }^{1,2,3}$ \\ I Virginia Institute for Psychiatric and Behavioral Genetics, Virginia Commonwealth University Medical Center, Richmond,Virginia, \\ United States of America \\ 2 Department of Human Genetics, Virginia Commonwealth University Medical Center, Richmond,Virginia, United States of America \\ 3 Department of Psychiatry, Virginia Commonwealth University Medical Center, Richmond, Virginia, United States of America \\ 4 Department of Psychology, Virginia Commonwealth University Medical Center, Richmond,Virginia, United States of America
}

\begin{abstract}
Several large studies have demonstrated that the Sliability to smoke cigarettes is strongly genetically influenced. However, the role of genetic and environmental risk factors in the use of other common forms of tobacco use has yet to be studied. Data on the regular use of cigarettes, cigars, pipes, dip (moist snuff), and chewing tobacco from 2634 male twins were analyzed with ACE structural equation models. Twin similarity for regular cigarette and dip use was largely genetic in origin. However, twin resemblance for chewing tobacco was just about equally the result of genes and shared environment, and twin similarity for use of pipes and cigars was entirely the result of shared environmental factors. Thus, the genetic influences on the liability for regular tobacco use appear to vary based on tobacco type. The causes for the use of different forms of tobacco are complex and worthy of further study.
\end{abstract}

Previous investigations on the genetic epidemiology of cigarette use have provided evidence that genetic factors strongly influence the liability for cigarette smoking (Li et al., 2003; Sullivan \& Kendler, 1999; Tyndale, 2003). A recent meta-analysis suggests that genetic factors account for approximately $60 \%$ of the liability for cigarette smoking initiation, and for $70 \%$ of the liability for nicotine dependence (Sullivan \& Kendler, 1999). There have been, to our knowledge, no investigations into the role of genetic and environmental risk factors for the use of tobacco forms other than cigarettes, despite evidence that noncigarette forms of tobacco use also pose substantial health risks. In this report, we investigate the genetic and environmental contributions to the liability to use the five common forms of tobacco in a population-based sample of male-male twin pairs.

\section{$\overline{\text { Method }}$}

The data for this paper were acquired as part of a large twin study conducted by the Virginia Adult
Twin Study of Psychiatric and Substance Use Disorders; details of sample acquisition and assessment have been published previously (Kendler et al., 2000). The sample consisted of 763 monozygotic (MZ) and 554 dizygotic (DZ) male twin pairs. Zygosity status was determined using a discriminant function analysis based on six standard zygosity questions (Kendler et al., 2000). This algorithm was designed using data from 227 twin pairs genotyped with at least eight highly polymorphic markers. The mean age of the final sample was $36.3+/-S D 9.1$ years (range 20 to 58 years). The average number of years of education was $13.7+/-2.45$ (range 3 to 20 years).

Subjects were asked a series of questions about their experiences with tobacco products as part of a structured questionnaire. Each twin was asked, 'Have you ever smoked or used tobacco regularly for at least a month?' If the respondent answered in the affirmative, then the number of cigarettes, cigars, pipes, dips (moist snuff), and chews (chewing tobacco) used per day during regular use was determined. Subjects were considered to have been regular users of a specific substance if the average weekly use exceeded seven cigarettes, dips, or chews, or three cigars or pipes for a month or more.

For each tobacco type, the statistical package $\mathrm{Mx}$ was used to fit standard ACE biometric models in order to partition the variance in liability for tobacco use (Neale et al., 1999); the principles of latent variable models for twin paradigms have been well-documented (Boomsma et al., 2002; Neale \& Cardon, 1992). These analyses employ a liability threshold model which assumes that liability for tobacco use is the normally distributed sum of genetic

Received 25 November, 2004; accepted 1 December, 2004.

Address for correspondence: Kenneth $S$. Kendler, Department of Psychiatry, Medical College of Virginia at Virginia Commonwealth University, Box 980126, Richmond, VA 23298-0126, USA. E-mail: kendler@hsc.vcu.edu 
and environmental effects (Kendler et al., 1992; Neale \& Cardon, 1992); the parameters were estimated by maximum likelihood (Edwards, 1972).

\section{$\overline{\text { Results }}$}

Cigarettes were by far the most common tobacco product consumed, with over half $(51.1 \%)$ of all subjects reporting regular use at some point in their lives. The other forms of smoked tobacco had substantially lower prevalences: only 1 in 20 subjects had used cigars regularly for at least a month, and pipe use had a similar frequency. The smokeless forms of tobacco both had regular use rates of approximately $10 \%$ in this sample. The correlations for both cigarettes and dip were substantially higher in the MZ group when compared to the DZ group (Table I), suggesting a genetic contribution to phenotypic variance. Other correlations were similar between groups.

The maximum likelihood parameter estimates from the ACE models are given in Table I. Cigarettes had the greatest genetic influence $\left(\mathrm{a}^{2}=.64\right)$, but dip also had a strong heritable component $\left(\mathrm{a}^{2}=.43\right)$; both of these effects were significantly greater than zero (cigarette $\chi^{2}=27.44, d f=1, p=<.0001 ; \operatorname{dip} \chi^{2}=4.38$, $d f=1, p=.0363$ ). We found no evidence for genetic effects on the liability to use cigars and pipes, while chewing tobacco had a small genetic influence. For cigars, pipes and chewing tobacco, the largest source of variance in liability to use was unique environment. For all forms of tobacco, parameter estimates imply that a modest portion of the variance in regular use is accounted for by environmental factors shared by members of a twin pair. Constraining all tobacco forms to have the same $\mathrm{a}^{2}, \mathrm{c}^{2}$, and $\mathrm{e}^{2}$ parameter estimates produced a model that fit the data significantly worse $\left(\chi^{2}=44.305, d f=12, p=<.0001\right)$ than one in which all forms were allowed to have independent parameters.

\section{$\overline{\text { Discussion }}$}

A central question in tobacco research is the extent to which genetic and environmental factors influence the liability for tobacco use. The present results imply that additive genetic effects have a strong influence on several forms of tobacco use, namely cigarettes, dip, and to a lesser extent, chewing tobacco, but surprisingly little effect on the liability to use cigars or pipes. Additionally, our analyses detected evidence that liability to use all tobacco forms measured were modestly influenced by that environment shared between twins, with variable contributions of the unique environment.

Several limitations of the study must be considered when interpreting these findings. First, the relatively low prevalence of pipe and cigar use increases the uncertainty of the parameter estimates for these tobacco forms. Further analyses with larger sample sizes will be required to characterize the genetic epidemiology of tobacco forms with greater precision. Second, our sample employed only Caucasian males and therefore generalizing these findings to other populations may not be appropriate. Finally, systematic differences in the environment between $\mathrm{MZ}$ and DZ groups could theoretically bias parameter estimates. However, previous studies have shown that this is not the case for several psychoactive substances, including cigarettes (Kendler \& Gardner, 1998; Kendler et al., 1993; Kendler et al., 1994; Lynskey et al., 2002).

Despite these potential limitations, these data suggest that the liability to use tobacco may be influenced not only by nicotine itself but also by the individual characteristics of the 'delivery device' used.

\section{Table 1}

Descriptive Statistics and Parameter Estimates

\begin{tabular}{|c|c|c|c|c|c|c|c|c|c|}
\hline & \multicolumn{2}{|c|}{ Prevalence } & \multicolumn{2}{|c|}{ Twin correlations } & \multicolumn{5}{|c|}{ Parameter estimates } \\
\hline & $\mathrm{MZ}$ & $\mathrm{DZ}$ & $\mathrm{MZ}$ & $\mathrm{DZ}$ & $a^{2}$ & $c^{2}$ & $e^{2}$ & Model & AIC \\
\hline Cigarettes & $48.4(736)$ & 54.9 (599) & $.80 \pm .03(263)$ & $.48 \pm .06(182)$ & $.64(.39-.85)$ & $.16(.00-.38)$ & $.20(.15-.26)$ & ACE & - \\
\hline \multirow[t]{2}{*}{ Cigars } & $4.6(70)$ & $5.5(60)$ & $.11 \pm .17(2)$ & $.38 \pm .14(5)$ & $.00(.00-.45)$ & $.26(.00-.46)$ & $.74(.52-.96)$ & ACE & - \\
\hline & & & & & - & $.26(.04-.46)$ & $.74(.54 .96)$ & CE & -2.00 \\
\hline \multirow[t]{2}{*}{ Pipes } & $4.3(66)$ & $4.6(50)$ & $.23 \pm .16(3)$ & $.42 \pm .15(4)$ & $.00(.00-.50)$ & $.32(.00-.52)$ & $.68(.47-.90)$ & ACE & - \\
\hline & & & & & - & $.32(.10-.52)$ & $.68(.48-.90)$ & CE & -2.00 \\
\hline \multirow[t]{2}{*}{ Dip } & $11.3(171)$ & $10.4(113)$ & $.72 \pm .05(40)$ & $.49 \pm .10(16)$ & $.43(.02-.79)$ & $.28(.00-.63)$ & $.29(.20-.41)$ & ACE & - \\
\hline & & & & & $.73(.62-.81)$ & - & $.27(.19-.38)$ & $\mathrm{AE}$ & -1.66 \\
\hline \multirow[t]{3}{*}{ Chewing } & $10.3(156)$ & $10.1(110)$ & $.41 \pm .09(19)$ & $.32 \pm .11(11)$ & $.19(.00-.56)$ & $.21(.00-.49)$ & $.59(.44-.76)$ & ACE & - \\
\hline & & & & & - & $.37(.23-.50)$ & $.63(.50-.77)$ & CE & -1.52 \\
\hline & & & & & $.43(.27-.58)$ & - & $.57(.42-.73)$ & $\mathrm{AE}$ & -1.22 \\
\hline
\end{tabular}

Note: Values in parentheses after prevalence percentages are individual-wise frequency counts. Cross-twin correlations for regular tobacco use in MZ or DZ twin pairs are estimated by tetrachoric correlation, with asymptotic standard errors given as well as the number of twin pairs concordant for use (in parentheses). Maximum likelihood estimates are given with $95 \%$ confidence intervals. $\mathrm{a}^{2}, \mathrm{c}^{2}$ and $\mathrm{e}^{2}$ are estimates of the proportion of variance in phenotype attributable to genetic, shared environment, and specific environmental liability respectively. When a more parsimonious submodel was suggested (by Akaike's Information Criteria, or AIC), parameters for these models are given. In the case of chewing tobacco, the CE and AE had comparable AIC values, therefore both are reported. 
Variations in genetic liability might be due to basic pharmacological attributes, such as differential bioavailability of nicotine based on tobacco type (Benowitz, 1988; Henningfield \& Keenan, 1993). Another possibility is that genetic influences on behavior, for example personality, predispose individuals to either initiate or continue using a particular form of tobacco (Frazier et al., 2000; Kendler, et al. 1993). The genetics of tobacco use are quite complicated and influenced by numerous genetic and environmental mediating variables. Further investigations, including multivariate approaches to the problem, are required to understand how products with similar origins and psychoactive ingredients could potentially have differential genetic influences on the liability to use them.

\section{Acknowledgments}

We would like to thank Steve Aggen PhD, John Hettema MD, PhD, and Kristen Jacobson PhD for their assistance. The Virginia Twin Registry, now part of the Mid-Atlantic Twin Registry directed by L. Corey and L. Eaves, provided subject access. Patsy Waring, Frank Butera, Sarah Woltz, Barbara Brooke and Lisa Halberstadt supervised data collection, Indrani Ray provided technical support. This work was supported by grants MH/DA-49492 and DA11287 from the NIH, from the Virginia Tobacco Settlement Foundation (Contract \#8520012) through the Virginia Youth Tobacco Project, VCU, NIMH grant MH-65322 to MCN, MH-20030 support of ES, and a fellowship to ES from VCU-MCV.

\section{References}

Benowitz, N. L. (1988). Drug therapy: Pharmacologic aspects of cigarette smoking and nicotine addition. The New England Journal of Medicine, 319, 1318-1330.

Boomsma, D., Busjahn, A., \& Peltonen, L. (2002). Classical twin studies and beyond. Nature Reviews. Genetics, 3, 872-882.

Edwards, A. W. F. (1972). Likelihood. London: Cambridge.

Frazier, A. L., Fisher, L., Camargo, C. A., Tomeo, C., \& Colditz, G. (2000). Association of adolescent cigar use with other high-risk behaviors. Pediatrics, 106, E26.

Henningfield, J. E., \& Keenan, R. M. (1993). Nicotine delivery kinetics and abuse liability. Journal of Consulting and Clinical Psychology, 61, 743-750.
Kendler, K. S., \& Gardner, C. O., Jr. (1998). Twin studies of adult psychiatric and substance dependence disorders: Are they biased by differences in the environmental experiences of monozygotic and dizygotic twins in childhood and adolescence? Psychological Medicine, 28, 625-633.

Kendler, K. S., Karkowski, L. M., Neale, M. C., \& Prescott, C. A. (2000). Illicit psychoactive substance use, heavy use, abuse, and dependence in a US population-based sample of male twins. Archives of General Psychiatry, 57, 261-269.

Kendler, K. S., Neale, M. C., Kessler, R. C., Heath, A. C., \& Eaves, L. J. (1992). A population-based twin study of major depression in women: The impact of varying definitions of illness. Archives of General Psychiatry, 49, 257-266.

Kendler, K. S., Neale, M. C., Kessler, R. C., Heath, A. C., \& Eaves, L. J. (1993). A test of the equal-environment assumption in twin studies of psychiatric illness. Behavior Genetics, 23, 21-27.

Kendler, K. S., Neale, M. C., Kessler, R. C., Heath, A. C., \& Eaves, L. J. (1994). Parental treatment and the equal environment assumption in twin studies of psychiatric illness. Psychological Medicine, 24, 579-590.

Kendler, K. S., Neale, M. C., MacLean, C. J., Heath, A. C., Eaves, L. J., \& Kessler, R. C. (1993). Smoking and major depression: A causal analysis. Archives of General Psychiatry, 50, 36-43.

Li, M. D., Cheng, R., Ma, J., \& Swan, G. (2003). A meta-analysis of estimated genetic and environmental effects on smoking behavior in male and female adult twins. Addiction, 98, 23-31.

Lynskey, M. T., Heath, A. C., Nelson, E. C., Bucholz, K. K., Madden, P. A., Slutske, W. S., Statham, D. J., \& Martin, N. G. (2002). Genetic and environmental contributions to cannabis dependence in a national young adult twin sample. Psychological Medicine, 32, 195-207.

Neale, M. C., Boker, S. M., Xie, G., \& Maes, H. H. (1999). Mx: Statistical modeling (5th ed.) [Computer software]. Richmond, VA: Department of Psychiatry, Medical College of Virginia.

Neale, M. C., \& Cardon, L. R. (1992). Methodology for genetic studies of twins and families. Dordrecht, the Netherlands: Kluwer Academic.

Sullivan, P. F., \& Kendler, K. S. (1999). The genetic epidemiology of smoking. Nicotine \& Tobacco Research, 1( Suppl. 2), 51-57.

Tyndale, R. F. (2003). Genetics of alcohol and tobacco use in humans. Annals of Medicine, 35, 94-121. 